\title{
Facility characteristics as independent prognostic factors of nursing home-acquired pneumonia
}

\author{
Che Wan Lim¹, Younghoon Choi ${ }^{1}$, Chang Hyeok An¹, Sang Joon Park ${ }^{1}$, Hee-Jin Hwang ${ }^{2}$, Jae Ho Chung ${ }^{3}$, \\ and Joo-Won Min $^{1}$
}

\begin{abstract}
${ }^{1}$ Division of Pulmonary and Critical Care Medicine, Department of Internal Medicine, Myongji Hospital, Seonam University College of Medicine, Goyang; ${ }^{2}$ Geriatric Center, Department of Family Medicine, ${ }^{3}$ Division of Pulmonology and Critical Care Medicine, Department of Internal Medicine, International St. Mary's Hospital, Catholic Kwandong University College of Medicine, Incheon, Korea
\end{abstract}

\section{Received: August 22, 2014}

Revised : November 20, 2014

Accepted: December 17, 2015

\author{
Correspondence to \\ Joo-Won Min, M.D. \\ Division of Pulmonary and \\ Critical Care Medicine, \\ Department of Internal Medi- \\ cine, Myongji Hospital, Seonam \\ University College of Medicine, 55 \\ Hwasu-ro 14beon-gil, \\ Deokyang-gu, Goyang 10475 , \\ Korea \\ Tel: +82-31-810-5419 \\ Fax: +82-31-969-0500 \\ E-mail: kmfindie@hanmail.net
}

Background/Aims: Recently, the incidence of nursing home-acquired pneumonia (NHAP) has been increasing and is now the leading cause of death among nursing home residents. This study was performed to identify risk factors associated with NHAP mortality, focusing on facility characteristics.

Methods: Data on all patients $\geq 70$ years of age admitted with newly diagnosed pneumonia were reviewed. To compare the quality of care in nursing facilities, the following three groups were defined: patients who acquired pneumonia in the community, care homes, and care hospitals. In these patients, 90-day mortality was compared.

Results: Survival analyses were performed in 282 patients with pneumonia. In the analyses, 90-day mortality was higher in patients in care homes $(12.2 \%$, $40.3 \%$, and $19.6 \%$ in community, care homes, and care hospitals, respectively). Among the 118 NHAP patients, residence in a care home, structural lung diseases, treatment with inappropriate antimicrobial agents for accompanying infections, and a high pneumonia severity index score were risk factors associated with higher 9o-day mortality. However, infection by potentially drug-resistant pathogens was not important.

Conclusions: Unfavorable institutional factors in care homes are important prognostic factors for NHAP.

Keywords: Nursing homes; Pneumonia; Prognosis

\section{INTRODUCTION}

The incidence of nursing home-acquired pneumonia (NHAP) is increasing, and it is now the leading cause of death among nursing home residents in Korea [1]. In the USA, the total number of cases of NHAP will approach 1.9 million episodes per year by 2030 [2], and the mortality rate in these patients is generally high, ranging from $13 \%$ to $41 \%$ [3].

Despite its high mortality rate, NHAP remains some- what undefined. In the 2005 American Thoracic Society/Infectious Diseases Society of America (ATS/IDSA) guidelines, NHAP was included in healthcare-associated pneumonia (HCAP) and considered to be a type of nosocomial pneumonia [4]. The definition of the term "nursing home" in NHAP is also vague. Although nursing home patients are generally defined as severely disabled elderly patients, the type of care provided by nursing homes is not specified [5,6]. Although some studies indicated that medical staff size and physician presence on- 
site are associated with decreased hospitalization rates in acute care centers $[7,8]$, few studies have examined outcomes after hospitalization. As the environment varies considerably among studies, the most effective antimicrobial treatments for NHAP remain controversial $[5,6,9-11]$.

There are two types of long-term care facility (LTCF) in Korea: care homes ([yoyangwon] in Korean) and care hospitals ([yoyangbyeongwon] in Korean). Care homes resemble assisted living facilities or intermediate care facilities, while care hospitals resemble skilled nursing facilities in the USA. Care homes are under the control of Long-Term Care Insurance for the Elderly (i.e., national insurance for seniors' welfare) and should be staffed by registered nurses (1 per 25 residents), physical therapists (1 per 100 residents), and social workers (1 per 100 residents), but not by physicians, who instead visit periodically. Care hospitals are under the control of the National Health Insurance system. Licensed physicians (1 per 40 residents) should supervise the care of each patient, and a nurse (one per six residents) or other medical professional is almost always on the premises.

In this study, we examined the clinical, microbiological, and institutional factors associated with risk of NHAP mortality.

\section{METHODS}

\section{Data collection}

Data on all patients $\geq 70$ years of age admitted with newly diagnosed pneumonia between January 2009 and December 2010 were retrospectively reviewed from the medical record database at Myongi Hospital, a community hospital in Goyang, Korea.

In all patients, pneumonia or other accompanying infections (e.g., urinary tract infection [UTI]) were diagnosed as reported previously [12]. Emergency department physicians and pulmonologists decided whether to hospitalize the patients. To exclude overt hospital-acquired pneumonia (HAP), patients with any current malignancy, end-stage renal disease undergoing renal replacement therapy, or advanced liver cirrhosis were excluded from the study. Patients with HCAP in the community were also excluded. Data of patients with "do not resuscitate" orders were not analyzed.
The protocol was approved by the Ethics Review Committee and the Institutional Review Board of Kwandong University Myongji Hospital (IRB No. 11-020).

\section{Microbiological studies}

Respiratory samples, including sputa and bronchial aspirates, were collected via endotracheal suction or bronchoscopy within 48 hours of hospitalization. To minimize possible bias due to incomplete sampling or contamination from the oral cavity, the predominance of cultured organisms was also reported in comparison with $\alpha$-hemolytic viridans group of streptococcus, representing part of the normal flora. Organisms more prominent than $\alpha$ streptococcus in adequate specimens were defined as pneumonia pathogens. Samples of most patients' blood and urine were cultured, and a urinary antigen test for Streptococcus pneumoniae was performed in most patients. However, investigations for Mycoplasma pneumoniae, Legionella pneumophila, and viruses were not performed in most patients.

Potentially drug-resistant pathogens (DRPs) were defined as those multidrug-resistant [13] or resistant to antibiotics used for CAP, such as Pseudomonas aeruginosa and Acinetobacter spp. In some patients, DRPs were cultured after empirical treatment with antimicrobial agents that did not cover these organisms. In these cases, the treatment was designated as "inappropriate."

\section{Classification of patients according to quality of care} CAP was defined as a diagnosis of pneumonia in patients who did not meet any of the criteria for HCAP. Hospitalized patients with CAP were considered as the current standard group, and were compared to patients with NHAP. To compare the quality of care in nursing facilities, patients with NHAP were classified into two groups. Thus, the following three groups were defined: patients who acquired pneumonia in (A) the community, (B) care homes, and (C) care hospitals.

\section{Statistical analysis}

The independent-samples $t$ test (Mann-Whitney $U$ test for nonparametric variables) was used for comparisons of continuous variables. The chi-square test (or Fisher exact test) and binary logistic regression were used for univariate and multivariate analyses, respectively, of categorical data. 
The Kaplan-Meier method was used to compare 90day mortality among the three groups, and mortality rates were assessed by log-rank test. Further risks were estimated using Cox proportional hazards models. Potential predictors for multivariate modeling were selected by univariate analyses and subsequently entered in a stepwise forward-conditional manner with entry and retention in the model set at a significance level of 0.05 . All analyses were performed using the SPSS version 18.0 (SPSS Inc., Chicago, IL, USA).

\section{RESULTS}

\section{Baseline characteristics}

Medical records of 989 pneumonia patients $\geq 70$ years of age were reviewed, and 707 patients were excluded from the analysis because they had overt HAP, malignancy, end-stage renal disease, or advanced liver cirrhosis (Fig. 1). Data were collected for 282 patients; 164 of these patients contracted pneumonia in community settings, while the remaining 118 cases were considered NHAP (67 patients contracted pneumonia in care homes, and 51 in care hospitals) (Table 1).

A greater proportion of patients $\geq 80$ years of age resided in care homes $(\mathrm{n}=49,73.1 \%)$ than in the community $(\mathrm{n}=82,50.0 \%)$ or in care hospitals $(\mathrm{n}=28,54.9 \%)$. Respiratory symptoms, such as cough and dyspnea, were frequently found in patients with CAP, and acute altered mental status was more frequent in patients with NHAP. Dementia and cerebrovascular diseases were common in patients with NHAP, and more than $60 \%$ of NHAP patients were bed-ridden $(67.2 \%$ of patients in care homes, and $80.4 \%$ of those in care hospitals). However, airway or structural lung diseases were more frequent in patients with CAP. More NHAP patients in care hospitals $(n=15,29.4 \%)$ had a history of hospitalization within the preceding 90 days compared with NHAP patients in care homes $(n=6,9.0 \%)$. In NHAP patients, pneumonia accompanied by UTI was common. Whereas $11.0 \%$ of CAP patients had a UTI, 31.3\% in care homes and $41.2 \%$ in care hospitals had pneumonia accompanied by a UTI. The same pathogens were discovered in respiratory and urinary tracts in only six patients $(10.0 \%$ of 60 pneumonia patients with UTI).

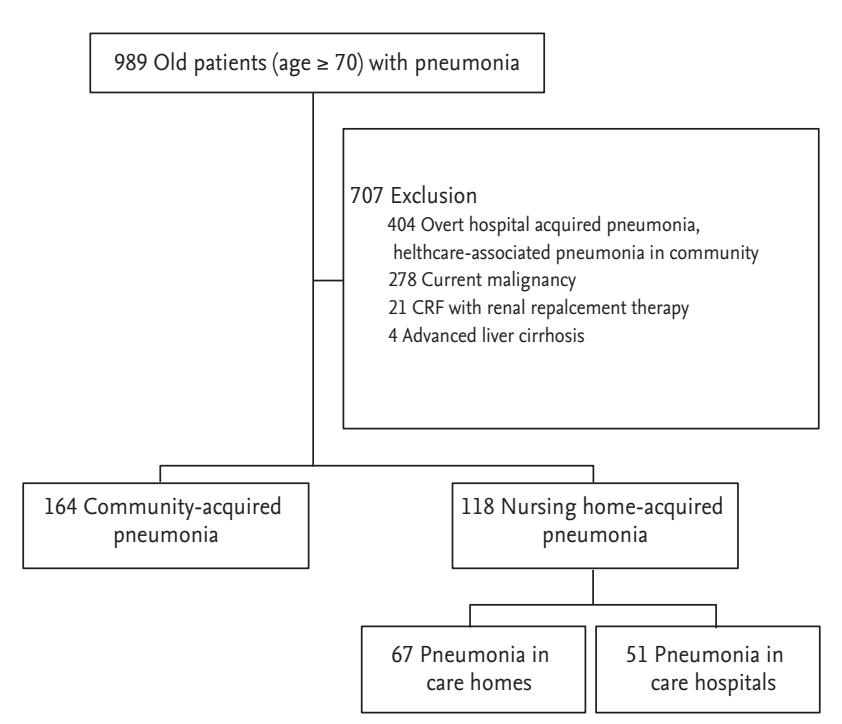

Figure 1. Flow diagram of 989 patients. CRF, chronic renal failure.

\section{Comparison of microbiology results and antimicro- bial treatments}

Pathogens were detected in respiratory specimens from less than half of the patients (Table 2). In each group, $S$. pneumoniae was the most frequent pathogen. More DRPs were detected in patients with NHAP than CAP, but the prevalence of pneumonia caused by DRPs did not differ between patients in care homes and those in care hospitals $(p=0.929)$. Whereas 23 CAP patients $(12.8 \%)$ were treated with antimicrobial agents for HAP according to ATS/IDSA guidelines for HAP, a greater proportion of NHAP patients were treated with these agents: 36 patients $(53.7 \%)$ in care homes and $34(66.7 \%)$ in care hospitals [4]. Initiation of inappropriate antibiotics was more frequent in patients with NHAP. Seventeen patients (25.4\%) in care homes and 18 (35.3\%) in care hospitals were initially treated with antimicrobial agents inappropriate for pneumonia or other accompanying infections (UTI and bacteremia). Although antimicrobial treatments did not differ between patients in care homes and care hospitals, more patients in care hospitals seemed to be treated inappropriately for accompanying infections, although this difference was not statistically significant (10.4\% vs. $23.5 \%$, respectively; $p=0.055$ ).

\section{Severity and treatment outcomes}

NHAP was more severe than CAP (Table 2). More NHAP patients than CAP patients had CRRB-65 (confusion, 
Table 1. Baseline clinical characteristics of pneumonia in the elderly $(\mathbf{n}=\mathbf{2 8 2})$

\begin{tabular}{|c|c|c|c|c|c|c|}
\hline \multirow[b]{2}{*}{ Characteristic } & \multirow[b]{2}{*}{ (A) $\operatorname{CAP}(n=164)$} & \multicolumn{2}{|c|}{ NHAP } & \multicolumn{3}{|c|}{$p$ value } \\
\hline & & $\begin{array}{c}\text { (B) Care homes } \\
(\mathrm{n}=67)\end{array}$ & $\begin{array}{c}\text { (C) Care hospitals } \\
(\mathrm{n}=5 \mathrm{l})\end{array}$ & $\mathrm{A} / \mathrm{B}$ & $\mathrm{A} / \mathrm{C}$ & $\mathrm{B} / \mathrm{C}$ \\
\hline Age, yr, range (median) & $70-100(79.5)$ & $71-96(84)$ & $71-93(81)$ & $0.001^{\mathrm{a}}$ & 0.957 & $0.004^{\mathrm{a}}$ \\
\hline$\geq 80$ & $82(50.0)$ & $49(73.1)$ & $28(54.9)$ & $0.001^{\mathrm{a}}$ & 0.541 & $0.039^{\mathrm{a}}$ \\
\hline Male sex & $93(56.7)$ & $31(47.0)$ & $29(56.9)$ & 0.149 & 0.984 & 0.254 \\
\hline \multicolumn{7}{|l|}{ Symptom } \\
\hline Cough & $122(74.4)$ & $40(59.7)$ & $27(52.9)$ & $0.027^{\mathrm{a}}$ & $0.004^{\mathrm{a}}$ & 0.463 \\
\hline Dyspnea & $91(55 \cdot 5)$ & $47(70.1)$ & $30(58.8)$ & $0.039^{\mathrm{a}}$ & 0.675 & 0.201 \\
\hline Fever & $34(20.9)$ & $13(19.4)$ & $11(21.6)$ & 0.804 & 0.914 & 0.772 \\
\hline Altered mentality & $23(14.0)$ & $37(55.2)$ & $30(58.8)$ & $<0.001^{\mathrm{a}}$ & $<0.001^{\mathrm{a}}$ & 0.696 \\
\hline \multicolumn{7}{|l|}{ Underlying disease } \\
\hline Dementia & $16(9.8)$ & $28(41.8)$ & $15(29.4)$ & $<0.001^{\mathrm{a}}$ & $<0.001^{\mathrm{a}}$ & 0.166 \\
\hline Cerebrovascular diseases & $31(18.9)$ & $23(34 \cdot 3)$ & $29(56.9)$ & $0.012^{\mathrm{a}}$ & $<0.001^{\mathrm{a}}$ & $0.015^{\mathrm{a}}$ \\
\hline Motor disturbances & $17(10.4)$ & $10(14.9)$ & $10(19.6)$ & 0.328 & 0.082 & 0.502 \\
\hline $\mathrm{CHF}$ & $5(3 \cdot 0)$ & $2(3.0)$ & $3(5 \cdot 9)$ & $>0.999$ & 0.398 & 0.651 \\
\hline Chronic heart diseases other than $\mathrm{CHF}$ & $22(13.4)$ & $8(11.9)$ & $8(15.7)$ & 0.762 & 0.683 & 0.556 \\
\hline Diabetes mellitus & $29(17.7)$ & $21(31.3)$ & $15(29.4)$ & $0.022^{\mathrm{a}}$ & 0.070 & 0.821 \\
\hline Hypertension & $73(44 \cdot 5)$ & $36(53.7)$ & $28(54.9)$ & 0.203 & 0.194 & 0.899 \\
\hline Airway diseases & $42(25 \cdot 6)$ & $3(4 \cdot 5)$ & $2(3 \cdot 9)$ & $<0.001^{a}$ & $0.001^{\mathrm{a}}$ & $>0.999$ \\
\hline Structural lung diseases & $23(14.0)$ & $3(4 \cdot 5)$ & $2(3 \cdot 9)$ & $0.037^{\mathrm{a}}$ & $0.049^{\mathrm{a}}$ & $>0.999$ \\
\hline Chronic kidney diseases & $7(4 \cdot 3)$ & $3(4 \cdot 5)$ & $2(3.9)$ & $>0.999$ & $>0.999$ & $>0.999$ \\
\hline Bed-ridden status & $22(13 \cdot 5)$ & $45(67.2)$ & $41(80.4)$ & $<0.001^{\mathrm{a}}$ & $<0.001^{\mathrm{a}}$ & 0.109 \\
\hline Hospitalization in the preceding 90 days & o & $6(9.0)$ & $15(29.4)$ & $0.001^{\mathrm{a}}$ & $<0.001^{\mathrm{a}}$ & $0.004^{\mathrm{a}}$ \\
\hline \multicolumn{7}{|l|}{ Pneumonia accompanied by } \\
\hline Urinary tract infection & $18(11.0)$ & $21(31.3)$ & $21(41.2)$ & $<0.001^{\mathrm{a}}$ & $<0.001^{a}$ & 0.269 \\
\hline Bacteremia & $11(6.7)$ & $7(10.4)$ & $9(17.6)$ & 0.336 & $0.027^{\mathrm{a}}$ & 0.258 \\
\hline Pulmonary tuberculosis & $5(3.0)$ & 0 & $1(2.0)$ & 0.325 & $>0.999$ & 0.432 \\
\hline
\end{tabular}

Values are presented as number (\%).

CAP, community-acquired pneumonia; NHAP, nursing home-acquired pneumonia; CHF, congestive heart failure.

${ }^{\mathrm{a}} \mathrm{p}<0.05$.

urea, respiratory rate and blood pressure) scores $\geq 3$ points and pneumonia severity index (PSI) scores $>130$ (class 5). The rates of admission to Intensive Care Units and in-hospital mortality were also higher in patients with NHAP. Most parameters associated with severity and treatment outcomes did not differ between patients in care homes and those in care hospitals, but the duration of admission was longer in pneumonia patients residing in care hospitals $(13.6 \pm 11.5$ vs. $22.0 \pm 20.3$, respectively; $p=0.023)$. There was no difference in the in-hospital mortality rate between patients in care homes and care hospitals (35.8\% vs. 19.6\%, respectively; $p=0.054)$.
In univariate log-rank tests, 90-day mortality was higher in patients in care homes (Fig. 2). Although there was no difference in mortality between CAP (12.2\%) and NHAP patients in care hospitals $(p=0.126)$, the patient mortality rate was higher in care homes $(40.3 \%)$ than in either the community $(12.2 \%$; $p<0.001)$ or in care hospitals (19.6\%; $p=0.011)$. Risk factors for 90 -day mortality are presented in Table 3. When all patients were included in the analysis, residence in a care home (adjusted hazard ratio [HR], 2.47; 95\% confidence interval [CI], 1.30 to 4.69), cerebrovascular disease (adjusted HR, 2.24; 95\% CI, 1.28 to 3.94), and pneumonia accompanied by a UTI (adjusted HR, 1.88; 95\% CI, 1.05 to 3.36), but not age, were 
Table 2. Comparison of microbiology, antimicrobial treatments, and clinical outcome in pneumonia in the elderly $(\mathrm{n}=\mathbf{2 8 2})$

\begin{tabular}{|c|c|c|c|c|c|c|}
\hline \multirow[b]{2}{*}{ Variable } & \multirow{2}{*}{$\begin{array}{l}(\mathrm{A}) \mathrm{CAP} \\
(\mathrm{n}=164)\end{array}$} & \multicolumn{2}{|c|}{ NHAP } & \multicolumn{3}{|c|}{$p$ value } \\
\hline & & $\begin{array}{c}\text { (B) Care homes } \\
(\mathrm{n}=67)\end{array}$ & $\begin{array}{l}\text { (C) Care hospitals } \\
(\mathrm{n}=51)\end{array}$ & $\mathrm{A} / \mathrm{B}$ & $\mathrm{A} / \mathrm{C}$ & $\mathrm{B} / \mathrm{C}$ \\
\hline \multicolumn{7}{|l|}{ Microbiology and antimicrobial treatments } \\
\hline \multicolumn{7}{|l|}{ Pathogens in respiratory specimens } \\
\hline Not detected & $107(65.2)$ & $34(50.7)$ & $27(52.9)$ & & & \\
\hline \multicolumn{7}{|l|}{ Gram-positive pathogens } \\
\hline Streptococcus pneumoniae & $20(12.1)$ & $7(10.5)$ & $8(15 \cdot 7)$ & & & \\
\hline \multicolumn{7}{|l|}{ Staphylococcus aureus } \\
\hline MSSA & $8(4 \cdot 9)$ & $3(4 \cdot 5)$ & 0 & & & \\
\hline MRSA & $1(0.6)$ & $6(9.0)$ & $4(7.8)$ & & & \\
\hline \multicolumn{7}{|l|}{ Gram-negative pathogens } \\
\hline Klebsiella pneumoniae & $14(8.5)$ & $9(13.4)$ & $4(7.8)$ & & & \\
\hline Haemophilus influenzae & $5(3.0)$ & O & o & & & \\
\hline Pseudomonas aeruginosa & $4(2.4)$ & $3(4 \cdot 5)$ & $3(5 \cdot 9)$ & & & \\
\hline Branhamella catarrhalis & $2(1.2)$ & $1(1.5)$ & o & & & \\
\hline Acinetobacter spp. & $1(0.6)$ & 0 & 0 & & & \\
\hline Escherichia coli & $1(0.6)$ & $4(6.0)$ & $1(2.0)$ & & & \\
\hline Proteus mirabilis & $1(0.6)$ & 0 & $3(5 \cdot 9)$ & & & \\
\hline \multicolumn{7}{|l|}{ Potential DRPs } \\
\hline In respiratory specimens & $6(3.7)$ & $14(20.9)$ & $11(21.6)$ & $<0.001$ & $<0.001$ & 0.929 \\
\hline In blood culture results & $5(3.0)$ & $4(6.0)$ & $6(11.8)$ & 0.287 & 0.024 & 0.325 \\
\hline In urine culture results & $3(1.8)$ & $8(11.9)$ & $12(23 \cdot 5)$ & 0.003 & $<0.001$ & 0.096 \\
\hline Antimicrobial therapy prior to admission & $24(14 \cdot 6)$ & $7(10.4)$ & $22(43.1)$ & 0.397 & $<0.001$ & $<0.001$ \\
\hline Initial antimicrobial treatments & & & & $<0.001$ & $<0.001$ & 0.156 \\
\hline Antibiotics covering CAP & $141(86.0)$ & $31(46.3)$ & $17(33 \cdot 3)$ & & & \\
\hline Antibiotics covering HAP & $23(14.0)$ & $36(53 \cdot 7)$ & $34(66.7)$ & & & \\
\hline Pseudomonas coverage & $22(13 \cdot 4)$ & $36(53 \cdot 7)$ & $32(62.7)$ & & & \\
\hline MRSA coverage & $1(0.6)$ & 0 & o & & & \\
\hline ESBL coverage & o & o & $2(3 \cdot 9)$ & & & \\
\hline Inappropriate initial antimicrobial agents & $12(7 \cdot 3)$ & $17(25 \cdot 4)$ & $18(35 \cdot 3)$ & $<0.001$ & $<0.001$ & 0.242 \\
\hline In pneumonia treatments & $8(4.9)$ & $12(17 \cdot 9)$ & $9(17 \cdot 6)$ & 0.001 & 0.006 & 0.970 \\
\hline In treatments of accompanied infections & $5(3.0)$ & $7(10.4)$ & $12(23 \cdot 5)$ & 0.043 & $<0.001$ & 0.055 \\
\hline \multicolumn{7}{|l|}{ Severity and treatment outcomes } \\
\hline CURB-65 score $\geq 3$ points & $59(36.0)$ & $45(67.2)$ & $32(62.7)$ & $<0.001$ & 0.001 & 0.617 \\
\hline PSI score > $130($ class 5) & $33(20.1)$ & $35(52.2)$ & $26(51.0)$ & $<0.001$ & $<0.001$ & 0.892 \\
\hline Duration of admission & $11.4 \pm 11.0$ & $13.6 \pm 11.5$ & $22.0 \pm 20.3$ & 0.447 & $<0.001$ & 0.023 \\
\hline ICU admission & $46(28.0)$ & $39(58.2)$ & $33(64 \cdot 7)$ & $<0.001$ & $<0.001$ & 0.473 \\
\hline In-hospital mortality & $16(9.8)$ & $24(35.8)$ & $10(19.6)$ & $<0.001$ & 0.059 & 0.054 \\
\hline
\end{tabular}

Values are presented as number (\%).

CAP, community-acquired pneumonia; NHAP, nursing home-acquired pneumonia; MSSA, methicillin-susceptible Staphylococcus aureus; MRSA, methicillin-resistant Staphylococcus aureus; DRP, drug resistant pathogen; HAP, home-acquired pneumonia; ESBL, extended spectrum $\beta$-lactamase; CURB, confusion, urea, respiratory rate and blood pressure; PSI, pneumonia severity index; ICU, Intensive Care Unit. 

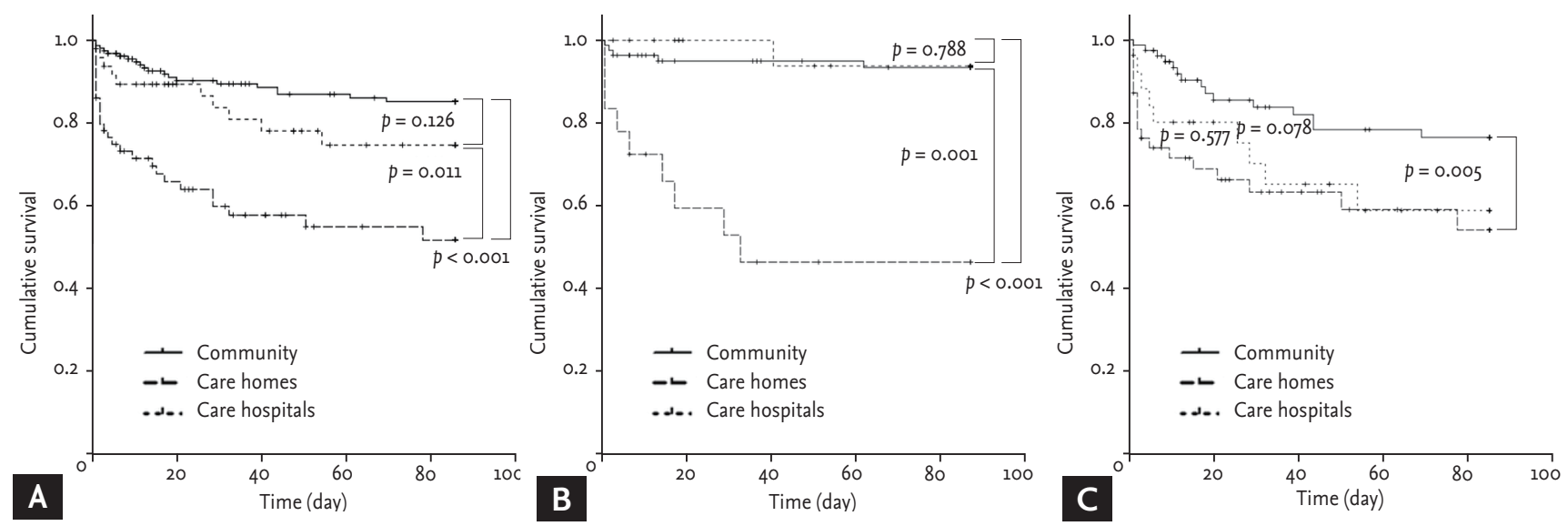

Figure 2. The 90 -day survival results of pneumonia patients by log-rank test. (A) All patients. (B) Patients $<80$ years of age. (C) Patients $\geq 80$ years of age.

Table 3. Risk factors of 9o-day mortality in pneumonia in the elderly, nursing home-acquired pneumonia, multivariate analy$\operatorname{ses}(n=282)$

\begin{tabular}{|c|c|c|c|c|c|c|}
\hline \multirow{2}{*}{ Factor } & \multicolumn{3}{|c|}{ Pneumonia in the elderly } & \multicolumn{3}{|c|}{$\operatorname{NHAP}(\mathrm{n}=118)$} \\
\hline & $\mathrm{HR}$ & $95 \% \mathrm{CI}$ & $p$ value & $\mathrm{HR}$ & $95 \% \mathrm{CI}$ & $p$ value \\
\hline \multicolumn{7}{|l|}{ Residence in long-term care facility } \\
\hline Community-acquired pneumonia & 1.00 & Reference & & & & \\
\hline Care hospitals & 0.69 & $0.30-1.60$ & 0.388 & 1.00 & Reference & \\
\hline Care homes & 2.47 & $1.30-4.69$ & 0.006 & 3.76 & $1.72-8.21$ & 0.001 \\
\hline \multicolumn{7}{|l|}{ Underlying disease } \\
\hline Cerebrovascular diseases & 2.24 & $1.28-3.94$ & 0.005 & & & \\
\hline Structural lung diseases & & & & 4.04 & $1.13-14.46$ & 0.032 \\
\hline Pneumonia accompanied by urinary tract infection & 1.88 & $1.05-3.36$ & 0.034 & & & \\
\hline $\begin{array}{l}\text { Inappropriate initial antimicrobial agents for } \\
\text { accompanying infection }\end{array}$ & & & & 2.61 & $1.24-5 \cdot 50$ & 0.012 \\
\hline PSI score $>130($ class 5$)$ & 3.70 & $2.00-6.86$ & $<0.001$ & 4.96 & $2.15-11.40$ & $<0.001$ \\
\hline
\end{tabular}

NHAP, nursing home-acquired pneumonia; HR, hazard ratio; CI, confidence interval; PSI, pneumonia severity index.

risk factors for mortality. Within the 118 NHAP patients, residence in a care home (adjusted HR, 3.76; 95\% CI, 1.72 to 8.21 ), structural lung diseases (adjusted HR, 4.04; $95 \%$ CI, 1.13 to 14.46 ), and treatment with inappropriate antimicrobial agents for accompanying infections (adjusted HR, 2.61; 95\% CI, 1.24 to 5.50) were risk factors. In both analyses, residence in a care home and a high PSI score, but not DRP infection, were factors significantly associated with 9o-day mortality.

\section{Risk factors for infection with potentially drug-resis- tant pathogens}

Risk factors associated with DRP infection are described in Table 4. In univariate analyses, residence in a nursing facility was an important factor related to DRP infection $(p<0.001)$. Cerebrovascular diseases $(p=0.014)$ and chronic kidney diseases $(p=0.032)$ were also important factors. Lack of consciousness during normal waking hours $(p=0.042)$, acutely altered mental state $(p<0.001)$, bed-ridden status $(p<0.001)$, and prior hospitalization $(p=0.004)$ were common in patients infected with DRPs. The risk of pneumonia caused by DRPs was higher when accompanied by UTI $(p=0.040)$ or other infections with DRPs $(p=0.002)$. Pneumonia caused by DRPs was more severe than that caused by drug-susceptible pathogens $(p=0.021)$. In multivariate analysis, the presence of 
Table 4. Risk factors of potentially DRP in pneumonia in the elderly $(\mathbf{n}=\mathbf{2 8 2})$

\begin{tabular}{|c|c|c|c|}
\hline Univariate analyses & Patients with DRPs $(\mathrm{n}=31)$ & Patients without DRPs $(n=251)$ & $p$ value \\
\hline Age $\geq 80$ years & $20(64.5)$ & $139(55 \cdot 4)$ & 0.333 \\
\hline \multicolumn{4}{|l|}{ Underlying disease } \\
\hline Cerebrovascular diseases & $15(48.4)$ & $68(27.1)$ & 0.014 \\
\hline Diabetes mellitus & $10(32.3)$ & $55(21.9)$ & 0.197 \\
\hline Hypertension & $22(71.0)$ & $115(45.8)$ & 0.008 \\
\hline Structural lung diseases & $3(9 \cdot 7)$ & $25(10.0)$ & $>0.999$ \\
\hline Chronic kidney diseases & $4(12.9)$ & $8(3.2)$ & 0.032 \\
\hline Residence in nursing facility & $25(80.6)$ & $93(37.1)$ & $<0.001$ \\
\hline Community-acquired pneumonia & $6(19 \cdot 4)$ & $158(62.9)$ & \\
\hline Care homes & $14(45 \cdot 2)$ & $53(21.1)$ & \\
\hline Care hospitals & $11(35 \cdot 5)$ & $40(15 \cdot 9)$ & \\
\hline \multicolumn{4}{|l|}{ Mentality } \\
\hline Lack of consciousness during normal waking hours & $4(12.9)$ & $9(3 \cdot 6)$ & 0.042 \\
\hline Acutely altered mental state & $19(61.3)$ & $71(28.3)$ & $<0.001$ \\
\hline Bed-ridden status & $24(77 \cdot 4)$ & $84(33.6)$ & $<0.001$ \\
\hline Hospitalization in the preceding 90 days & $7(22.6)$ & $14(5 \cdot 6)$ & 0.004 \\
\hline Antimicrobial therapy prior to admission & $8(25.8)$ & $45(17 \cdot 9)$ & 0.289 \\
\hline \multicolumn{4}{|l|}{ Pneumonia accompanied by } \\
\hline Urinary tract infection & $11(35 \cdot 5)$ & $49(19 \cdot 5)$ & 0.040 \\
\hline Other infections with DRPs & $8(25.8)$ & $16(6.4)$ & 0.002 \\
\hline \multicolumn{4}{|l|}{ Severity } \\
\hline CURB-65 score $\geq 3$ points & $21(67.7)$ & $115(45.8)$ & 0.021 \\
\hline PSI score > $130($ class 5$)$ & $15(48.4)$ & $79(31.5)$ & 0.059 \\
\hline ICU admission & $18(58.1)$ & $100(39.8)$ & 0.052 \\
\hline
\end{tabular}

Values are presented as number (\%).

DRP, drug-resistant pathogen; CURB, confusion, urea, respiratory rate and blood pressure; PSI, pneumonia severity index; ICU, Intensive Care Unit.

chronic kidney diseases (adjusted odds ratio [OR], 4.30; 95\% CI, 1.08 to $17.05 ; p=0.038)$ and bed-ridden status (adjusted OR, 6.68; 95\% CI, 2.74 to 16.26; $p<0.001$ ) were significantly associated with DRP infection.

\section{DISCUSSION}

The most important finding of this study was that residence in a care home was an independent risk factor for 90-day mortality in NHAP, and that facility characteristics had a greater influence on mortality risk than microbiological factors.

Many recent studies have examined the relationship between prognosis of NHAP and infection with DRPs. Although DRPs were more frequent in NHAP than CAP patients, DRP infection did not increase NHAP mortality $[6,10]$. This is contrary to the hypothesis that excess mortality is related to inadequate treatment for DRPs using antimicrobial treatments for CAP [6]. Some investigators have suggested that NHAP should not be treated as nosocomial pneumonia [14] and host factors such as age and comorbidity should be considered as potential risk factors for mortality $[6,9]$. In the present study, DRPs in respiratory specimens did not contribute significantly to the risk of mortality. Only accompanying infections, such as UTIs, and treatment with inappropriate antimicrobial agents exhibited significant associ- 
ations with mortality. Further high-quality randomized controlled trials are required to determine the effects of antimicrobial treatments [2,11,14-17].

In this study, residence in a care home was an important prognostic factor for 90-day mortality. Several recent studies have revealed the prognostic importance of environmental factors. In a study of HCAP, nursing home residence was the main risk factor for mortality [18]. Several studies performed in nursing homes showed that medical staff organization, nurse turnover, and staff attitude regarding treatment guidelines were important risk factors for hospitalization in acute-care centers [19-22]. In the present study, the associations of environmental, host, clinical, and microbiological factors with mortality were analyzed simultaneously. Residence in a facility with fewer registered nurses or physical therapists, or without an on-site physician, was associated with increased 90-day mortality of NHAP. Inadequate pre-hospitalization management could explain the increased mortality rate in care home residents. Although many factors were similar in patients in care homes and care hospitals, fewer patients in care homes were treated with antibiotics. The availability of fewer registered nurses or physical therapists may result in poor oral hygiene or lack of nursing care help with activities of daily living. The clinical significance of pre-hospitalization factors remains to be determined in further studies.

This study was limited by its retrospective nature. In addition, the facility characteristics in this study may be unique to Korea. However, most studies associated with LTCFs tend to have limited value because (1) available medical resources are always limited in LTCFs and (2) long-term care systems are diverse in all countries. Another limitation of this study is that there was a paucity of data regarding nursing facilities, so reasonable interpretation of the results is difficult. As there have been no Korean studies of nursing facilities, it was impossible to consider pre-hospitalization factors. We assumed that unfavorable institutional factors, such as residence in a facility with fewer registered nurses and without a fulltime physician, would be important prognostic factors for NHAP. These pre-hospitalization factors should be considered in the design of future trials to identify the optimal antimicrobial treatments.

In conclusion, unfavorable institutional factors were important prognostic factors for NHAP. However, fur- ther studies are required to understand this result.

\section{KEY MESSAGE}

1. Residence in a care home is an independent risk factor for 90-day mortality in pneumonia in the elderly, and facility characteristics had a greater influence on mortality risk than microbiological factors. However, further studies are required to interpret these results.

2. These pre-hospitalization factors should be taken into consideration in the design of future trials to identify the optimal antimicrobial treatments and outcome measurements.

\section{Conflict of interest}

No potential conflict of interest relevant to this article was reported.

\section{REFERENCES}

1. Cho YJ, Jung BK, Ahn JS. A comparative study of nursing home-acquired pneumonia with community-acquired pneumonia. Tuberc Respir Dis 2011;70:224-234.

2. El-Solh AA, Niederman MS, Drinka P. Management of pneumonia in the nursing home. Chest 2010;138:14801485 .

3. Mylotte JM. Nursing home-acquired pneumonia. Clin Infect Dis 2002;35:1205-1211.

4. American Thoracic Society; Infectious Diseases Society of America. Guidelines for the management of adults with hospital-acquired, ventilator-associated, and healthcare-associated pneumonia. Am J Respir Crit Care Med 2005;171:388-416.

5. Ewig S, Welte T, Chastre J, Torres A. Rethinking the concepts of community-acquired and health-care-associated pneumonia. Lancet Infect Dis 2010;10:279-287.

6. Ewig S, Klapdor B, Pletz MW, et al. Nursing-home-acquired pneumonia in Germany: an 8-year prospective multicentre study. Thorax 2012;67:132-138.

7. Fama T, Fox PD. Efforts to improve primary care delivery to nursing home residents. J Am Geriatr Soc 1997;45:627632.

8. Zimmer JG, Eggert GM, Treat A, Brodows B. Nursing 
homes as acute care providers: a pilot study of incentives to reduce hospitalizations. J Am Geriatr Soc 1988;36:124129 .

9. Klapdor B, Ewig S, Schaberg T, et al. Presentation, etiology and outcome of pneumonia in younger nursing home residents. J Infect 2012;65:32-38.

10. Polverino E, Dambrava P, Cilloniz C, et al. Nursing home-acquired pneumonia: a 10 year single-centre experience. Thorax 2010;65:354-359.

11. El-Solh AA, Niederman MS, Drinka P. Nursing home-acquired pneumonia: a review of risk factors and therapeutic approaches. Curr Med Res Opin 2010;26:2707-2714.

12. Stone ND, Ashraf MS, Calder J, et al. Surveillance definitions of infections in long-term care facilities: revisiting the McGeer criteria. Infect Control Hosp Epidemiol 2012;33:965-977.

13. Magiorakos AP, Srinivasan A, Carey RB, et al. Multidrug-resistant, extensively drug-resistant and pandrug-resistant bacteria: an international expert proposal for interim standard definitions for acquired resistance. Clin Microbiol Infect 2012;18:268-281.

14. Ma HM, Wah JL, Woo J. Should nursing home-acquired pneumonia be treated as nosocomial pneumonia? J Am Med Dir Assoc 2012;13:727-731.

15. El-Solh AA. Nursing home acquired pneumonia: approach to management. Curr Opin Infect Dis 2011;24:148-
151.

16. El Solh AA. Nursing home-acquired pneumonia. Semin Respir Crit Care Med 2009;30:16-25.

17. Ma HM, Ip M, Hui E, Chan PK, Hui DS, Woo J. Role of atypical pathogens in nursing home-acquired pneumonia. J Am Med Dir Assoc 2013;14:109-113.

18. Depuydt P, Putman B, Benoit D, Buylaert W, De Paepe P. Nursing home residence is the main risk factor for increased mortality in healthcare-associated pneumonia. J Hosp Infect 2011;77:138-142.

19. Lima JC, Intrator O, Karuza J, Wetle T, Mor V, Katz P. Nursing home medical staff organization and 30-day rehospitalizations. J Am Med Dir Assoc 2012;13:552-557.

20. Linnebur SA, Fish DN, Ruscin JM, et al. Impact of a multidisciplinary intervention on antibiotic use for nursing home-acquired pneumonia. Am J Geriatr Pharmacother 2011;9:442-450.e1.

21. El-Solh AA, Alhajhusain A, Saliba RG, Drinka P. Physicians' attitudes toward guidelines for the treatment of hospitalized nursing home-acquired pneumonia. J Am Med Dir Assoc 2011;12:270-276.

22. Zimmerman S, Gruber-Baldini AL, Hebel JR, Sloane PD, Magaziner J. Nursing home facility risk factors for infection and hospitalization: importance of registered nurse turnover, administration, and social factors. J Am Geriatr Soc 2002;50:1987-1995. 